\title{
A importância das medidas multidimensionais de pobreza para a administração pública: um exercício em Palmeira das Missões (RS)*
}

\author{
Janaina Ottonelli** \\ Solange Regina Marin*** \\ Melody Porsse**** \\ Sirlei Glasenapp ${ }^{* * * * *}$
}

SumÁrio: 1. Introdução; 2. O conceito e as medidas multidimensionais de pobreza; 3. Aspectos metodológicos; 4. Considerações finais: a noção e as medidas multidimensionais de pobreza e a administração pública.

Summary: 1. Introduction; 2 . The concept and multidimensional measures of poverty; 3. Methodological aspects; 4 . Final remarks: the notion and multidimensional measures of poverty and public administration.

\footnotetext{
* Artigo recebido em set. 2010 e aceito em jan. 2011. Uma primeira versão do trabalho foi apresentada no IV Enapegs, Lavras, MG, 2010.

** Graduada em administração pelo Cesnors/UFSM (RS). Mestranda em economia regional da Universidade Federal do Rio Grande do Norte (UFRN). Endereço: Rua Floriano Peixoto, 1750, sala 611 - Centro — CEP 90015-372, Santa Maria, RS, Brasil. E-mail: janainaottonelli@gmail. com.

*** Graduada em ciências econômicas pela Universidade Estadual de Maringá (UEM), mestre em desenvolvimento rural pela Universidade Federal do Rio Grande do Sul (UFRS) e doutora em desenvolvimento econômico pela Universidade Federal do Paraná (UFPR). Professora adjunta do Departamento de Ciências Econômicas da Universidade Federal de Santa Maria (UFSM). Endereço: Rua Floriano Peixoto, 1750, sala 611 - Centro - CEP 90015-372, Santa Maria, RS, Brasil. E-mail: marin@smail.ufsm.br.

**** Graduação em ciências econômicas pela Universidade Estadual de Maringá (UEM), mestrado em economia pela Universidade Federal da Paraíba (UFPB) e doutorado em administração pela Universidade Federal do Rio Grande do Sul (UFRGS). Bolsista de pós-doutorado no Programa de Pós-Graduação em Economia da Pontifícia Universidade Católica do Rio Grande do Sul (PUC-RS). Endereço: Av. Diógenes Ribeiro de Lima, 2811, bloco 1, ap. 22 - CEP 05458-002, São Paulo, SP, Brasil. E-mail: msporsse@gmail.com.

$* * * * *$ Mestrado em engenharia de produção pela Universidade Federal de Santa Maria (UFSM). Professora da UFSM/Campus de Silveira Martins. Endereço: UFSM — Campus de Silveira Martins, Rua Francisco Guerino, 407 — CEP 97195-000, Silveira Martins, RS, Brasil. E-mail: sglasenapp11@gmail.com.
} 
Palavras-chave: pobreza; administração pública; abordagem das capacitações.

KEY WORDS: poverty; public administration; capability approach.

O principal objetivo deste artigo é mostrar que as medidas multidimensionais de pobreza são importantes para a administração pública, tendo em vista que apresentam diferentes características das pessoas pobres a serem atendidas por políticas públicas. Através dessas medidas, é possível identificar as dimensões de vida em que a população é mais privada e, consequentemente, focalizar as políticas para melhor suprir essas necessidades. Para tanto, o artigo fundamenta-se conceitualmente na Abordagem das Capacitações de Sen $(1985,2000,2001)$ e apresenta uma medida multidimensional de pobreza construída para o município de Palmeira das Missões (RS), a partir de um instrumento de pesquisa baseado nos trabalhos de Barros, Carvalho e Franco (2003) e Santos (2007). Os resultados demonstram que a pobreza vista de uma perspectiva mais ampla, como a medida calculada para o município de Palmeira das Missões, pode apontar uma realidade diferente para a dinâmica da pobreza e, dessa forma, alterar o foco da política de combate à pobreza para ser mais efetiva. Nesse sentido, as medidas multidimensionais de pobreza são relevantes para a administração pública, uma vez que caracterizam melhor a realidade, auxiliando no entendimento de suas causas e na proposta de políticas.

The importance of multidimensional measures of poverty for public administration: an exercise in Palmeira das Missões (RS)

The main aim of this article is to show that multidimensional measures of poverty are important for public administration in so far as they present different characteristics of the poor people to be attended by public policies. Through these measures, it is possible to identify the dimensions of life in which the population is most deprivate and, consequently, focus policies in order to better address these needs. The article is based on Sen's (1985, 2000, 2001) Capability Approach and presents a multidimensional measure of poverty for the municipality of Palmeira das Missões (RS), which was developed having as basis a research instrument used by Barros, Carvalho e Franco (2003) and Santos (2007). The results show that poverty viewed in a broader perspective, as the calculated for the municipality of Palmeira das Missões, may appoint a different reality for the dynamics of poverty and, in that way, to amend the focus of policy for combating poverty to be more effective. Accordingly, the multidimensional measures of poverty are relevant for public administration, once that characterize better the reality, helping in understanding their causes and in proposing policies.

\section{Introdução}

Quando se fala em pobreza, existe um consenso de que pobres são apenas aquelas pessoas que não disponibilizam de recursos monetários necessários 
à sua sobrevivência. Apesar de ser uma dimensão importante da pobreza, o nível de renda não captura completamente outras privações das pessoas, tais como ter uma vida perigosa, difícil e dolorosa, podendo ser prematuramente abreviada; ter uma vida privada de conhecimento e comunicação; ser excluído da voz e poder das instituições do Estado e da sociedade; ter dignidade, confiança e autorrespeito roubados.

Em função disso, nos últimos anos, a noção de pobreza tem passado por uma evolução no sentido de incluir dimensões importantes sobre a vida das pessoas e não ficar limitada apenas à esfera da disponibilidade de renda. Essa evolução foi acompanhada também de uma busca incessante por medidas multidimensionais da pobreza (Programa das Nações Unidas para o Desenvolvimento, 1997, 2000).

Este artigo, fundamentado nos trabalhos de Sen (1985, 1993, 1999, 2001) sobre a Abordagem das Capacitações, apresenta o argumento de que uma pessoa pode ser pobre por não ter acesso aos serviços básicos como educação, saúde, energia elétrica, água encanada, saneamento básico e, ainda, por não ter liberdade de escolha entre diferentes tipos de vida que valoriza ter. Como pobreza pode ser entendida em uma perspectiva multidimensional e ser atribuída a diferentes fatores, seu estudo e entendimento tornam-se relevantes para aqueles interessados nas questões inerentes à administração pública, dado que uma política de combate à pobreza será mais efetiva se atender às dimensões corretas.

Nesse contexto, o principal objetivo deste artigo é mostrar a importância das medidas multidimensionais de pobreza, resultado da noção complexa de pobreza, para a administração pública, uma vez que através das mesmas é possível identificar as reais privações da população, auxiliando na proposta de políticas.

Para tanto, além dessa introdução, este artigo aborda, em um primeiro momento, as diversas acepções para a noção de pobreza e as medidas que delas se originam. Posteriormente, apresenta-se uma medida multidimensional de pobreza construída para a cidade de Palmeira das Missões (RS) como uma tentativa de diagnosticar outras faces da pobreza a serem atendidas por políticas públicas, bem como as consequentes mudanças no foco das políticas em função do uso dessa perspectiva mais ampla. Por último, as considerações finais relacionam a noção e as diferentes medidas de pobreza com a administração pública, ressaltando que o conceito de pobreza e suas medidas podem influenciar o sucesso de uma política pública, visto a necessidade de se conhecer não somente quem são as pessoas pobres, mas, especialmente, em quais dimensões de vida essas pessoas possuem maiores privações. 


\section{2. $\mathbf{O}$ conceito e as medidas multidimensionais de pobreza}

Segundo Codes (2008), existem pelo menos quatro diferentes acepções para a noção de pobreza: as ideias da subsistência, das necessidades básicas, da privação relativa e da pobreza como privação de capacitação. Na primeira noção unidimensional, tem-se a interpretação da pobreza como sendo absoluta, ligada a questões de sobrevivência física. A segunda passa a configurar uma abordagem multiface da pobreza e inclui certo mínimo de requerimentos de uma família para consumo: comida, abrigo, roupas e necessidades de serviços providos por e para a comunidade como um todo, como água potável, serviços sanitários, transporte público, saúde, educação e acesso a cultura. A terceira é definida em função do contexto social em que se vive, a partir da consideração do padrão de vida e da maneira como as diferentes necessidades são supridas em uma dada realidade socioeconômica. A pobreza relativa é definida por comparação, ou seja, pobreza é um estado de carência relativamente a outras situações sociais com que é confrontado (Rocha apud Codes, 2008). A quarta, derivada da Abordagem das Capacitações de Sen $(1985,1993,1999,2001)$, alega que a noção de pobreza não deve ser identificada com o critério padrão de escassez de renda, mas sim como privação das capacitações básicas.

Essas diferentes formas de entendimento do que é ser pobre originam as várias medidas de pobreza. Considerando o espaço informacional renda como critério de avaliação da pobreza, é possível definir a linha de indigência e a linha de pobreza. A linha de indigência considera as pessoas que conseguem adquirir, com sua renda monetária, uma cesta de alimentos que contenha quantidade calórica mínima à sobrevivência física (Comim e Bagolin, 2002; Santos, 2007). Esta linha define a pobreza absoluta, ou seja, as pessoas abaixo dela são consideradas indigentes, absolutamente pobres. Segundo Picolotto (2005) e Santos (2007), a medida de pobreza absoluta pode ser definida de maneira idêntica em qualquer lugar do mundo, pois é determinada com base em valores monetários. Essa medida se ajusta aos países pobres, porque nesses locais a questão da sobrevivência é de grande relevância.

A linha de pobreza corresponde ao valor da linha de indigência acrescido de valor monetário correspondente às despesas básicas de transporte, vestuário e habitação (Comim e Bagolin, 2002; Santos, 2007). As pessoas com renda abaixo da linha de pobreza são consideradas relativamente pobres. A pobreza relativa difere de lugar para lugar, referindo-se à exclusão social dos indivíduos em relação à sociedade em que vivem. É mais utilizada em países ricos, pois "define necessidades a serem satisfeitas em função do modo de 
vida predominante em determinada sociedade, o que resulta incorporar a redução das desigualdades sociais como objetivo de políticas públicas" (Santos, 2007:21).

Para exemplificar essa segunda medida, dois indivíduos são comparados, um que vive nos Estados Unidos e outro na Nigéria. Ambos são pobres, ou seja, estão situados abaixo da linha de pobreza e não têm algumas de suas necessidades básicas satisfeitas. Eles desejam obter o que o modo de vida da sociedade em que vivem oferece. Logo, o que a sociedade americana oferece é diferente do que a sociedade nigeriana oferece, já que a primeira sociedade está situada no grupo dos países de Primeiro Mundo e a segunda, no grupo dos países de Terceiro Mundo.

Tradicionalmente, a pobreza tem sido definida como insuficiência de renda monetária, tendo seu caráter estritamente econômico enfatizado. Essa medida ainda é preferencialmente utilizada devido à facilidade de agregação e comparação dos índices entre regiões e países e é comumente utilizada pela administração pública para a definição de quais pessoas são pobres e, consequentemente, atendidas por uma política pública de combate à pobreza (Comim e Bagolin, 2002; Waquil e Mattos, 2003).

Apesar de a medida unidimensional ser amplamente empregada como orientação de políticas de combate à pobreza, existe uma evolução acerca do caráter multiface da pobreza, que, por sua vez, requer medidas multidimensionais. Essa evolução acompanha a discussão sobre o conceito de desenvolvimento humano.

Os estudos de Sen $(1981,1993,1999,2000,2002)$ mostram que há a necessidade de considerar outras variáveis, além da renda, para medir a pobreza, tais como acesso à educação, saúde, habitação, saneamento e também a liberdade de escolha entre os tipos de vida que uma pessoa tem razão de valorizar. Para o referido autor, a pobreza pode ser entendida como um processo de privação de capacitações para funcionar ou, em outros termos, o ser pobre significa não ter a habilidade para viver uma vida valiosa (Laderchi, 2001). Especificamente, pobreza é definida conforme algumas capacitações básicas que são requeridas para satisfazer certos funcionamentos relevantes, tais como ser adequadamente nutrido, levar uma vida longa, saudável e criativa, ser alfabetizado, ter acesso ao conhecimento e comunicação, desfrutar de um decente padrão de vida, de liberdade, dignidade e autorrespeito. Dessa forma, ser pobre abrange múltiplos aspectos, quantitativos e qualitativos, que incluem insuficiência de renda, acesso a bens, educação, saúde, gênero, origem étnica, circunstâncias familiares, localização geográfica, entre outros (Programa das Nações Unidas para o Desenvolvimento, 1997). 
Seguindo os ensinamentos de Sen (1981, 1985, 1993), o Relatório de Desenvolvimento Humano do Programa das Nações Unidas para o Desenvolvimento (1997) definiu a pobreza como a negação de oportunidades e escolhas que são básicas para o desenvolvimento humano e para se viver uma vida digna, constituindo-se em uma medida multidimensional preocupada com a qualidade de vida das pessoas. Essa noção de pobreza será aprofundada a seguir.

\section{Pobreza como privação de capacitações e a perspectiva de multidimensionalidade}

Segundo Sen (1981), passar fome é uma característica de alguns indivíduos não terem o que comer. Não é a característica de não existir comida suficiente para se comer, embora a não existência do alimento possa ser uma das causas para as pessoas não possuírem alimentos.

Desse modo, as condições para conceituar a pobreza são, primeiramente, definir quem deve ser o foco do estudo, ou seja, identificar os pobres; especificar o conceito de pobreza baseado nas condições dos pobres; e utilizar um método para agregar as características de um grupo de pessoas pobres dentro de uma visão ampla de pobreza (agregação).

Entre as diferentes noções e medidas de pobreza, Sen (2000) ressalta que o estudo da pobreza deve ser entendido em diferentes espaços informacionais e que a pobreza poderia ser vista como insuficiência de capacitações. Para poder falar de insuficiência de capacitações, é preciso conceituar as partes constituintes da abordagem seniana, ou seja, os funcionamentos e as capacitações.

O conceito de "funcionamentos", que tem raízes distintamente aristotélicas, reflete várias coisas que uma pessoa pode considerar valioso fazer ou ser. Os funcionamentos valorizados podem variar dos elementares, como ser adequadamente nutrido e livre de doenças evitáveis, a atividades ou estados pessoais muito complexos, como poder participar da vida da comunidade e ter respeito próprio (Sen, 2000:95).

A "capacitação" [capability] de uma pessoa consiste nas combinações alternativas de funcionamentos cuja realização é factível para ela. Portanto, a capacitação é um tipo de liberdade: a liberdade substantiva de realizar combinações alternativas de funcionamentos (ou, menos formalmente expresso, a liberdade para ter estilos de vida diversos) (Sen, 2000:95).

Para melhor exemplificar os funcionamentos e as capacitações, Sen (2000) cita o exemplo de duas pessoas: uma rica que decide jejuar e uma po- 
bre que passa fome. Em relação ao funcionamento "estar bem alimentadas", ambas estão no mesmo funcionamento, ou seja, estão passando fome. Porém, as duas pessoas possuem capacitações diferentes; a pessoa rica teve a liberdade (oportunidade) de escolher passar fome; já a pessoa pobre não teve a oportunidade de escolha entre jejuar ou não jejuar. As opções de escolhas são diferentes para as duas pessoas, uma vez que a segunda não tem a liberdade de escolher não passar fome.

A Abordagem das Capacitações avalia então as oportunidades da pessoa em termos de sua habilidade atual de atingir os vários funcionamentos como parte do viver (Sen, 1993). O que está em discussão é a caracterização da oportunidade da pessoa em uma forma objetiva, isto é, por meio de seu conjunto de funcionamentos. Por isso, Sen (2002) entende pobreza como um fenômeno multiface e ressalta que "Privação é melhor vista em termos de falta de certos funcionamentos básicos (tais como ser fisicamente saudável), ao invés de em termos de variáveis tais como renda ou consumo de calorias que devem ser vistas como meios e não como fins em si mesmos" (Sen, 2002:42).

Seguindo essa abordagem, é possível argumentar que o objetivo principal da ação pública é a expansão das capacitações dos indivíduos para realizar seus seres e fazeres mais valorados. Assim, a Abordagem das Capacitações pode servir como uma guia para os objetivos a serem seguidos em uma batalha contra a fome e a pobreza desde que considera os seres e fazeres das pessoas e suas capacitações correspondentes.

Ressalta-se que com a contribuição seniana a discussão da pobreza caminhou para uma ampliação do fenômeno a ser investigado e analisado, no sentido de incluir múltiplas dimensões consideradas relevantes para a caracterização do ser pobre. Nesse sentido, a Abordagem das Capacitações pode ser interpretada como uma extensão da perspectiva rawlsiana da "justiça como equidade". Nessa perspectiva, focada na igualdade de oportunidades para as pessoas realizarem seus projetos de vida, a atenção é voltada sobre os meios gerais úteis (Sen, 2000, 2001). Tais meios são os "bens primários", os quais todas as pessoas racionais deveriam desejar para desenvolverem seus planos de vida, independentemente de quais sejam seus respectivos planos. Os "bens primários" incluem cinco conjuntos de bens: (1) direitos e liberdades básicas; (2) liberdades de movimento e liberdades de escolha de uma posição em um contexto de oportunidades iguais; (3) capacidades, poderes e prerrogativas relacionadas às várias funções e posições de responsabilidade nas instituições políticas e econômicas; (4) renda e riqueza; (5) bases sociais do autorrespeito (Vero, 2001). 
De acordo com os dois princípios da justiça ${ }^{1}$ na teoria de Rawls (1997), estes "bens primários" são os objetos a serem distribuídos e igualados (Biondo, 2001) para que os indivíduos tenham oportunidades iguais de realizarem seus objetivos. Com efeito, as instituições têm o papel de distribuir aos indivíduos estes meios gerais úteis para a promoção de seus projetos de vida, meios que são essenciais para se alcançar a igualdade social.

A concentração de Rawls (1997) sobre os "bens primários" demonstra seu reconhecimento da multidimensionalidade dos fatores que afetam o bemestar individual e a liberdade, claramente negligenciados em análises mais estreitas, como é o caso da análise baseada na renda. Entretanto, ao considerar que são os "bens primários" que devem ser distribuídos e igualados, o citado autor não atenta para a questão das variações no uso de uma mesma quantidade de mercadorias por diferentes indivíduos, assumindo que as diversas pessoas têm iguais habilidades em transformar mercadorias em bem-estar e liberdades (Biondo, 2001).

Ao invés disso, as pessoas diferentes variam grandemente na maneira de converter o mesmo pacote de bens em oportunidades de alcançar seus projetos de vida, além de diferirem também em suas necessidades de bens (Biondo, 2001; Nussbaum, 2000). Tratar dois indivíduos A e B como "igualmente muito bem" (Nussbaum, 2000:69), exatamente porque ambos têm a mesma quantia de mercadorias, é negligenciar duas vidas distintas e separadas, que desfrutam de circunstâncias diferentes.

As diferenças entre os indivíduos podem ser classificadas em físicas, sociais e culturais. Primeiramente, as pessoas divergem em suas habilidades físicas para converter "bens primários" em realizações para elas. Pode-se tomar como exemplo as necessidades nutricionais, cuja variação depende da idade da pessoa, do sexo, da ocupação e da propensão à doença. Uma pessoa doente e outra saudável, uma mulher grávida ou uma mulher que está amamentando, uma criança e um adulto, todos apresentam diferentes necessidades nutricionais, mesmo consumindo uma quantidade igual de alimento.

\footnotetext{
${ }^{1}$ No primeiro princípio da justiça, cada indivíduo deve ter um direito igual a um sistema abrangente de liberdades básicas iguais, o qual deve ser compatível com um sistema similar de liberdades para todos. No segundo princípio, as desigualdades sociais e econômicas devem satisfazer a duas condições: (1) elas "devem estar associadas a cargos e posições abertos a todos"; (2) "devem ser para o maior benefício dos membros da sociedade que têm menos vantagens" (Sen, 2001:129130). Este segundo princípio inclui o "Princípio da Diferença" (Rawls, 1997), no qual se deve promover o maior benefício daqueles que apresentam menos vantagens, sendo essas vantagens identificadas com ter o menor valor do índice de "bens primários" (Sen e Foster, 1997).
} 
Em segundo lugar, as variações sociais e culturais em diferentes comunidades, concernentes a tradições hierárquicas, geram também desigualdades na conversão de "bens primários". Tal é o caso de leis e práticas discriminatórias contra as mulheres, limitando-as de usufruir, em um mesmo caminho que os homens, do pacote de "bens primários" e, consequentemente, das liberdades que esse pacote pode oferecer (Nussbaum, 2000; Biondo, 2001).

No caso de restrições culturais aceitas pela sociedade, a métrica dos "bens primários" não abrange tal questão, na medida em que em situações de permanente desigualdade e práticas discriminatórias, as pessoas mais prejudicadas formam suas preferências de acordo com a situação e tendem a se conformar com a mesma (fenômeno das preferências adaptativas). Desse modo, embora algumas pessoas tenham menos oportunidades comparadas a outras, elas não expressam seu desconforto com o padrão de vida, porque aceitam a situação (Biondo, 2001).

Em suma, os contextos físico, social e cultural afetam as habilidades dos indivíduos em transformar bens ou recursos em realizações. Dadas as diferenças na conversão, a igualdade de oportunidades, ou liberdades, usufruídas pelas diferentes pessoas para realizarem seus fins, não pode ser gerada pela igualdade na distribuição de "bens primários".

$\mathrm{O}$ fato de a linha que separa ricos de pobres não considerar somente a renda ou os "bens primários", mas igualmente diversos elementos - como saúde, educação, habitação, direitos econômicos e sociais, igualdade entre os sexos, participação econômica e política, liberdades políticas, entre outros —, abre novas perspectivas de análise. Há, por exemplo, a possibilidade de se contemplarem situações em que as necessidades relativas aos domínios não monetários da pobreza sejam satisfeitas, sem que a pobreza monetária seja eliminada (Mestrum apud Codes, 2008).

No sentido de colaborar para a interpretação e análise do fenômeno pobreza em uma esfera multifacetada, foram desenvolvidas medidas também compatíveis com a evolução do pensamento científico sobre o que é ser pobre. ${ }^{2}$ O Índice de Desenvolvimento Humano (IDH), o Índice de Desenvolvimento Humano Municipal (IDH-M), o Índice de Desenvolvimento Familiar (IDF) e o Índice de Pobreza Familiar (IPF) podem ser citados como medidas multidimensionais que têm como base o conceito de pobreza seniano. Atualmente,

\footnotetext{
${ }^{2}$ Para mais detalhes sobre o IDH, ver Programa das Nações Unidas para o Desenvolvimento (2007). De outros índices, tais como o IDH-M, ver Santos (2007). Para o IDF, ver Barros, Carvalho e Franco (2003); e o IPF, ver Silva e Barros (2006).
} 
pode-se afirmar que existe um consenso sobre o caráter multidimensional da pobreza, que demanda formas cada vez mais amplas e complexas de medição. Porém, cabe ressaltar o argumento de Mestrum (apud Codes, 2008) de que por mais pertinente que seja a abordagem da pobreza como fenômeno multidimensional, ela apresenta dificuldades, tais como a dificuldade da avaliação quantitativa - problema em agregar diferentes dimensões em um único indicador devido à questão de como ponderar cada uma delas - e o perigo de correr o risco de confundir suas diferentes dimensões com a pobreza propriamente dita e deixar em último plano a questão da renda.

Portanto, a evolução do pensamento científico em torno do fenômeno pobreza também parece ser acompanhada de esforços de medição, que por tratarem de múltiplas dimensões e diferentes ponderações, ainda precisam de desenvolvimentos, como a necessidade da inclusão de informações desagregadas e valorativas na avaliação da pobreza para que se possam descobrir quais são as privações sofridas pelas pessoas. Contudo, essas medidas mais amplas são ferramentas indispensáveis para administradores públicos envolvidos com políticas públicas de combate à pobreza, já que caracterizam melhor a pobreza na realidade e auxiliam na proposta de políticas. A partir disso, a seguir será apresentada a criação de uma medida de pobreza multidimensional, desenvolvida para uma amostra de mulheres na cidade de Palmeira das Missões (RS), como uma tentativa de diagnosticar outras faces da pobreza a serem atendidas por políticas públicas, bem como de analisar o que as pessoas consideram como mais importante para suas vidas.

\section{Aspectos metodológicos}

Para a elaboração de uma medida multidimensional de pobreza, tendo como background a Abordagem das Capacitações seniana, foi elaborado um instrumento de pesquisa, baseado nos trabalhos de Barros, Carvalho e Franco (2003) e Santos (2007), aplicado junto à população-alvo na cidade de Palmeira das Missões (RS).

A população-alvo da pesquisa foi definida a partir de dados já cadastrados em um programa estadual — Primeira Infância Melhor (PIM) — que visa o desenvolvimento infantil através de um trabalho conjunto entre as visitadoras do programa e as mães (e famílias) de crianças de zero a seis anos das famílias mais pobres do município de Palmeira das Missões. ${ }^{3}$ O Programa Pri-

\footnotetext{
${ }^{3}$ Para mais informações sobre o PIM como política pública, ver Schneider e Ramires (2007).
} 
meira Infância Melhor (PIM) foi lançado no estado do Rio Grande do Sul em 2003, através da assinatura da Portaria no 15/2003, que o instituiu e definiu as responsabilidades do Estado e dos municípios.

A partir dos dados socioeconômicos do PIM foi possível encontrar uma fonte de informações sobre características de diferentes famílias que poderiam ser usadas na pesquisa. Tendo em vista esses fatores, optou-se por trabalhar com 100 mulheres que participam do programa. Essas mulheres residem em três diferentes bairros: Área Verde, Seis de Maio e Santa Catarina.

A decisão de entrevistar apenas mulheres se deu pelo fato de elas serem consideradas as formadoras do conhecimento dos filhos, principalmente nos bairros mais pobres, onde muitas mulheres não trabalham fora e, assim, passam a maior parte de seu tempo com seus filhos. Essa decisão segue também o argumento de Sen (2000) sobre o importante papel das mulheres no processo de desenvolvimento como expansão das capacitações humanas por serem vistas "como agentes ativos de mudança: promotoras dinâmicas de transformações sociais que podem alterar a vida das mulheres e dos homens" (Sen, 2000:220-221). Além disso, existem provas consideráveis de que o ganho de poder e a "educação e alfabetização das mulheres tende a reduzir as taxas de mortalidade das crianças" (Sen, 2000:227).

Balatchandirane (2003) também faz afirmações sobre a importância das mulheres no desenvolvimento humano. Conforme o autor, principalmente em países subdesenvolvidos, a educação exerce um impacto significativo na vida das mulheres, pois traz independência econômica, eleva o nível de consciência política, de sensibilização social e de conscientização sobre os cuidados necessários com a saúde. Destaca ainda que, quando as mulheres são instruídas e possuem rendimentos, elas produzem impactos favoráveis não só na área da saúde, mas também na educação, no desenvolvimento das crianças e também no que diz respeito à proteção ao meio ambiente e gestão dos recursos naturais.

Antes da elaboração do instrumento de pesquisa, foram feitas visitas aos diferentes bairros para o conhecimento da realidade de vida material das pessoas. Após a visita e a leitura de outras pesquisas realizadas em outras regiões do país, foi elaborada uma primeira versão do instrumento com a definição de algumas dimensões de vida das pessoas. Essa primeira versão foi apresentada e discutida junto com as visitadoras do PIM que trabalham diretamente com as mães das crianças de zero a seis anos de idade. As visitadoras consideraram as dimensões já apresentadas no instrumento como representativas do tipo de vida das mulheres. Esse encontro com as visitadoras teve o objetivo de incluir no instrumento de pesquisa o maior número possível de dimensões de vida 
que fossem valoradas pelas mulheres atendidas pelo programa PIM. O esforço era para captar, ao máximo, o que seria considerado de valor pelas mulheres, porém a partir da ótica de vida das visitadoras.

Desse encontro com as visitadoras foram sugeridas outras dimensões como importantes, tais como ter um bom relacionamento familiar e ter filhos protegidos. Após a discussão do instrumento e seu teste junto às visitadoras, foram realizadas as visitas às 100 mulheres. Cada entrevistador era acompanhado por uma visitadora do PIM que desempenhava o papel de mediadora nas entrevistas.

O instrumento de pesquisa foi elaborado com 12 dimensões compostas por 93 indicadores que procuram englobar o que as mulheres valorizam em termos de suas próprias vidas. Destaca-se que as dimensões realmente importantes para as mulheres teriam de ser determinadas pelas próprias mulheres. Todavia, como essa é a primeira pesquisa e se caracteriza como piloto, optouse por trabalhar com o PIM pelo fato de que, além do cadastro com dados sobre as famílias, as visitadoras conhecem cada uma das famílias que fazem parte do programa, sendo possível construir o instrumento de pesquisa a partir dos relatos das visitadoras.

Para suprimir o problema da escala de valores pessoais atribuídos por cada pessoa em particular, ao final do questionário foram apresentadas todas as dimensões e pediu-se às mulheres para classificarem cada uma das dimensões como sendo pouco importante, importante ou muito importante. Isso permitiria a construção de um ranking das dimensões e o estabelecimento de pesos diferenciados para dimensões conforme o que cada mulher considera como de valor para si mesma.

Porém, alguns problemas surgem quando se trata de conhecer a escolha social. Primeiramente, as mulheres não sabiam classificar, porque nunca antes tinham parado para pensar sobre suas vidas. Num segundo momento, a dificuldade está no grau de confiabilidade dado às respostas, porque as mulheres, por não apresentarem, em sua maioria, uma perspectiva de futuro, também não possuem uma visão crítica sobre suas próprias vidas, fato que atrapalha na atribuição de valor às diferentes dimensões apresentadas. Para efeito de construção da medida de pobreza, optou-se por adotar pesos iguais para todas as dimensões em razão das dificuldades encontradas no estabelecimento de valores pelas próprias mulheres entrevistadas. No entanto, mesmo com os problemas discutidos, foi solicitado às mulheres que classificassem as dimensões conforme a importância. Essa classificação não foi utilizada na construção da medida de pobreza, como apresentado, mas consistiu em uma informação adicional que pode ser comparada aos resultados da pesquisa para uma melhor análise. 
As informações levantadas no instrumento de pesquisa possibilitaram o cálculo de uma medida de pobreza multidimensional. Cada dimensão desdobra-se em indicadores, que funcionam como uma pergunta, que tem resposta "sim" ou "não". Além disso, cada pergunta investiga se a família em questão tem limitação ou não tem limitação para a realização daquele funcionamento. Cada "sim" mostra que a família não tem limitação para a realização do funcionamento e assume valor um. Já a resposta "não" constitui uma limitação e, por isso, assume valor zero. Ou seja, cada indicador resulta em uma variável binária que assume valor zero (0) ou um (1).

Por exemplo, na dimensão "morar bem" que é composta por 11 indicadores, na primeira pergunta "sua moradia é própria?", a resposta "sim" mostra a inexistência de limitação para a realização do funcionamento "morar bem".

A construção da medida de pobreza multidimensional é obtida da seguinte forma:

$$
I N D_{F}=\frac{\sum_{i=1}^{n} Q_{i}}{n}
$$

Onde:

$I N D_{F}=$ medida por família

$n=$ quantidade de Questões (Q)

$Q\left\{\begin{array}{l}1 \\ 0\end{array}\right.$, isto é, $Q$ assume valor 0 ou 1

Por exemplo, tomando por base a dimensão "morar bem" para uma das famílias, tem-se:

$$
I N D_{F}=\frac{1+1+1+1+1+1+1+1+1+0+0}{11}=0,82
$$

Essa mesma medida para o grupo de mulheres de um determinado bairro seria:

$$
I N D_{G}=\frac{\sum_{i=1}^{m} I N D_{F_{i}}}{m}
$$

Onde:

$I N D_{G}=$ medida por grupo de mulheres de determinado bairro $m=$ quantidade de famílias 
Como o índice varia de 0 a 1 , quanto mais próximo de 0 estiver o índice obtido, mais limitações para a realização dos seus funcionamentos uma família terá. Ao contrário, quanto mais próximo de 1 estiver a medida, menores as limitações para os funcionamentos.

Ressalta-se que esse índice pode ser obtido para cada família por dimensão considerada e como uma média de todas as dimensões. Também pode ser uma medida global para cada dimensão ou como uma média de todas as dimensões. O que definirá qual índice a ser usado é o objetivo de política pública a ser seguido. Por exemplo, se o objetivo é descobrir em qual dimensão as pessoas pobres têm mais limitações, o interessante é o cálculo do índice para cada família em cada uma das dimensões.

\subsection{Pobreza de que em Palmeiras das Missões?}

Algumas das informações obtidas no instrumento de pesquisa, ${ }^{4}$ composto por 12 dimensões e 93 indicadores, podem ser visualizadas no quadro 1 .

Quadro 1

Alguns indicadores das 12 dimensões

\begin{tabular}{|llcc|}
\hline Indicadores (frequência) & Sim & Não & Total \\
\hline Sua moradia é própria? & 85 & 13 & 98 \\
Possui banheiro dentro de casa? & 72 & 26 & 98 \\
Existe cama para todos os moradores da casa? & 66 & 32 & 98 \\
Você pratica algum esporte? & 06 & 92 & 98 \\
Você já fez exame ginecológico? & 68 & 30 & 98 \\
Você sabe como se prevenir contra doenças sexualmente & 85 & 13 & 98 \\
transmissíveis? & & & \\
Você está empregada? & 10 & 88 & 98 \\
Você trabalha com carteira assinada? & 01 & 97 & 98 \\
Você já frequentou a escola? & 92 & 06 & 98 \\
\hline
\end{tabular}

Continua

\footnotetext{
${ }^{4}$ Ao final das visitas às 100 mulheres, os instrumentos de pesquisa foram revisados e dois tiveram de ser desconsiderados para a análise final, totalizando, portanto, 98 instrumentos aplicados válidos.
} 


\begin{tabular}{|llll|}
\hline Indicadores (frequência) & Sim & Não & Total \\
\hline Existe algum adulto com secundário completo? & 11 & 87 & 98 \\
Existe algum adulto com alguma educação superior? & 01 & 97 & 98 \\
Não há (houve) adolescente grávida na família? & 79 & 19 & 98 \\
Sua casa possui energia elétrica? & 91 & 07 & 98 \\
Você tem acesso a água encanada? & 89 & 09 & 98 \\
Há drenagem para esgoto? & 42 & 56 & 98 \\
Você já realizou tudo que esperava realizar na sua vida? & 25 & 73 & 98 \\
Você se considera uma pessoa feliz? & 87 & 11 & 98 \\
Você teme pelo futuro de seu filho? & 83 & 15 & 98 \\
Você nunca precisou reduzir a quantidade de alimentos por falta de & 33 & 65 & 98 \\
dinheiro? & & & \\
Todos da casa recebem no mínimo três alimentações diárias? & 82 & 16 & 98 \\
Você possui recursos para comprar roupas e calçados? & 47 & 51 & 98 \\
Você nunca deixou de ir a algum lugar porque não achava que estava & 33 & 65 & 98 \\
devidamente vestida? & & & 98 \\
Você pode contar com os vizinhos no caso de necessidade? & 81 & 17 & 98 \\
Você costuma se reunir com alguém para tomar chimarrão? & 82 & 16 & 98 \\
Você participa de algum culto religioso? & 88 & 10 & 98 \\
Você e seu companheiro estão juntos a mais de um ano? & 77 & 21 & 98 \\
Toda a renda da família é recebida na forma de salário? & 49 & 49 & 98 \\
A família recebe algum tipo de transferência do governo? & 74 & 24 & 98 \\
\hline
\end{tabular}

Fonte: Elaborado pelas autoras a partir dos dados primários da pesquisa de campo.

De acordo com o quadro 1, os indicadores da dimensão "morar bem" mostram que 85 das entrevistadas possuem casa própria, 72 têm banheiro dentro das casas e 66 têm cama para todos os moradores. Os indicadores da dimensão "ter boa saúde" foram: apenas 6 praticam esporte, 66 fizeram exame ginecológico e 85 afirmaram saber como se prevenir contra doenças sexualmente transmissíveis.

Na dimensão "ter trabalho gratificante" foi verificado que 10 estavam empregadas (apenas uma trabalhava com carteira assinada), e 23 disseram que metade dos membros da família encontrava-se ocupada. Já em relação à dimensão "ter acesso ao conhecimento", 92 frequentaram a escola, 11 disseram que nas suas famílias havia algum adulto com ensino secundário e apenas 
uma respondeu que em sua família havia adulto com ensino superior. Na dimensão "ter filhos protegidos": 50 disseram que as crianças praticavam esporte e 19 afirmaram que houve adolescente grávida na família.

As respostas das entrevistadas para os indicadores da dimensão "ter acesso aos serviços básicos" foram que 91 possuem energia elétrica, 89 têm acesso a água encanada e 42 têm drenagem para esgoto em suas casas.

Os indicadores da dimensão "ter perspectiva para o futuro" foram: 25 já realizaram tudo o que desejavam em suas vidas, 87 se consideram felizes e 83 temem pelo futuro de seus filhos. Na dimensão "comer adequadamente", 65 já precisaram reduzir a quantidade de alimentos por falta de dinheiro e 82 disseram que todos na família fazem no mínimo as três refeições diárias.

Quanto aos indicadores da dimensão "vestir-se adequadamente", 47 das entrevistadas afirmaram que possuem recursos para adquirir roupas e calçados e 33 nunca deixaram de ir a algum lugar porque achavam que não estavam devidamente vestidas. E em relação à dimensão "participar da vida da comunidade", 81 podem contar com os vizinhos em caso de necessidade, 82 costumam se reunir com alguém para tomar chimarrão e 88 participam de algum culto religioso.

"Ter bom relacionamento familiar" teve como indicadores citados: você vive com seus filhos e companheiros e você e seu companheiro vivem juntos há mais de um ano, o primeiro obtendo 79 e o segundo, 77 respostas afirmativas.

Por fim, "ter disponibilidades de recursos" teve como indicadores: se toda a renda da família é recebida na forma de salário, e se a família recebe algum tipo de transferência do governo, o primeiro tendo 49 respostas afirmativas e o segundo, 74 .

A partir dos indicadores apresentados foi possível verificar quais as privações sofridas pelas entrevistadas. Destacam-se algumas como: a falta de cama para todos os integrantes da família, a falta de cuidados com a saúde, o alto índice de entrevistadas em situação de desemprego, a baixa escolaridade das entrevistadas e de seus familiares. Verificou-se também o alto número de residências sem drenagem de esgoto (fator que ocasiona a proliferação de doenças) e o elevado número de famílias dependentes de transferências governamentais.

Além de obter esses dados, o instrumento de pesquisa trazia ao final todas as dimensões consideradas para serem classificadas pelas mulheres como pouco importante, importante e muito importante (quadro 2). Algumas dimensões consideradas muito importantes foram "ter saúde" e "ter filhos protegidos". Como pouco importantes foram citadas "vestir-se adequadamente" e "participar da vida da comunidade". 
Quadro 2

Classificação das dimensões realizada pelas mulheres

\begin{tabular}{|l|c|c|c|c|}
\hline \multirow{2}{*}{ Dimensões } & \multicolumn{3}{|c|}{ Alternativas (frequência) } \\
\cline { 2 - 5 } & $\begin{array}{c}\text { Pouco } \\
\text { Importante }\end{array}$ & Importante & $\begin{array}{c}\text { Muito } \\
\text { Importante }\end{array}$ & Total \\
\hline 1. Morar bem & 5 & 28 & 65 & 98 \\
\hline 2. Ter boa saúde & 0 & 17 & 81 & 98 \\
\hline 3. Ter trabalho & 0 & 27 & 71 & 98 \\
\hline 4. Ter acesso ao conhecimento & 4 & 28 & 66 & 98 \\
\hline 5. Ter filhos protegidos & 0 & 10 & 88 & 98 \\
\hline 6. Ter acesso a serviços básicos & 1 & 35 & 62 & 98 \\
\hline 7. Ter perspectiva para o futuro & 5 & 38 & 55 & 98 \\
\hline 8. Comer adequadamente & 2 & 27 & 69 & 98 \\
\hline 9. Vestir-se adequadamente & 10 & 34 & 54 & 98 \\
\hline 10. Participar da vida da comunidade & 11 & 43 & 44 & 98 \\
\hline 11. Ter bom relacionamento & 1 & 22 & 75 & 98 \\
\hline 12. Ter disponibilidade de recursos & 1 & 20 & 77 & 98 \\
\hline
\end{tabular}

Fonte: Elaborado pelas autoras a partir de dados primários da pesquisa de campo.

Ao comparar as informações geradas pelos quadros anteriores, pode-se perceber que, apesar de as entrevistadas apresentarem maior privação nas dimensões "ter acesso ao conhecimento" e "ter disponibilidade de recursos", elas consideraram de maior importância as dimensões "ter saúde" e "ter filhos protegidos". Esse fato indica que as mulheres entrevistadas não sabem definir quais as dimensões nas quais sofrem maior privação, pois residem em bairros pobres, com alta incidência de violência e criminalidade, de infraestrutura deficiente (ruas sem pavimentação, iluminação precária, ausência do serviço de recolhimento de lixo, de redes de esgoto e em alguns locais há a ausência de rede elétrica e hídrica) e falta de patrulhamento policial. Portanto, para estas mulheres as dimensões referentes à saúde e à segurança são as que possuem maior valor em suas vidas, pois não valoram ter conhecimento e recursos financeiros para levar uma vida com melhores condições.

O quadro 3 mostra o índice multidimensional para o grupo de mulheres $\left(I N D_{G}\right)$ para cada uma das 12 dimensões consideradas no instrumento de pesquisa. A análise desse índice pode ser feita para cada bairro isoladamente ou para o conjunto deles. 
Se for realizada uma análise por bairro, é possível argumentar que as mulheres residentes no bairro Santa Catarina são as pessoas de maior limitação para a realização dos funcionamentos "morar bem", "ter boa saúde", "ter trabalho gratificante", "ter acesso ao conhecimento" e "comer e vestir-se adequadamente", mostrado pelos menores $I N D_{G}$. As mulheres residentes no bairro Área Verde têm mais limitação na realização dos seguintes funcionamentos: "ter acesso a serviços básicos" e "ter disponibilidade de recursos". As mulheres residentes no bairro Seis de Maio têm mais limitação na realização dos seguintes funcionamentos: "ter filhos protegidos", "ter perspectiva de futuro" e "participar da vida da comunidade".

É possível identificar, com o cálculo do índice multidimensional, em quais dimensões as pessoas pobres possuem maiores limitações para sua efetiva realização e, consequentemente, serem alvo de uma política pública de combate à pobreza.

No caso dos três bairros, as mulheres residentes no Santa Catarina são as que possuem mais limitação em um maior número de funcionamentos. Ou seja, pode-se argumentar que as mulheres desse bairro são mais privadas do que as mulheres dos outros dois bairros.

Quando analisamos os índices para os três bairros, é possível verificar que mais limitação existe na realização dos funcionamentos: "ter disponibilidade de recursos", "ter acesso ao conhecimento", "ter trabalho gratificante", "ter perspectiva de futuro" e "ter acesso a serviços básicos". A menor limitação está na realização dos seguintes funcionamentos: "ter bom relacionamento familiar", "ter filhos protegidos", "participar da vida da comunidade", "comer adequadamente", "vestir-se adequadamente" e "ter boa saúde".

\section{Quadro 3}

Índice multidimensional por grupo de famílias para cada dimensão

\begin{tabular}{|l|c|c|c|c|c|c|}
\hline Bairro & $\begin{array}{c}\mathbf{I N D}_{G} \\
\text { (morar bem) }\end{array}$ & $\begin{array}{c}\text { INDG } \\
\text { (ter boa saude) }\end{array}$ & $\begin{array}{c}\text { INDG } \\
\text { (ter trabalho gratificante) }\end{array}$ & $\begin{array}{c}\text { INDG } \\
\text { (ter acesso ao conhecimento) }\end{array}$ & $\begin{array}{c}\text { INDG } \\
\text { (ter filhos protegidos) }\end{array}$ & $\begin{array}{c}\text { INDG } \\
\text { (ter acesso a senicos) }\end{array}$ \\
\hline Área Verde & 0,62 & 0,65 & 0,60 & 0,42 & 0,85 & 0,50 \\
\hline Seis de Maio & 0,72 & 0,63 & 0,45 & 0,59 & 0,74 & 0,61 \\
\hline $\begin{array}{l}\text { Santa } \\
\text { Catarina }\end{array}$ & 0,60 & 0,60 & 0,35 & 0,24 & 0,75 & 0,57 \\
\hline TOTAL & 0,65 & 0,63 & 0,47 & 0,42 & 0,78 & 0,56 \\
\hline
\end{tabular}

Fonte: Elaborado pelas autoras a partir dos dados primários da pesquisa de campo. 
Quadro 3

Índice multidimensional por grupo de famílias para cada dimensão (continuação)

\begin{tabular}{|c|c|c|c|c|c|c|}
\hline Bairro & $\underset{\text { (ter perspectiva) }}{\mathrm{IND}_{\mathrm{G}}}$ & $\underset{\text { (comer adequadamente) }}{\mathrm{IND}_{\mathrm{G}}}$ & $\begin{array}{l}\mathrm{IND}_{\mathrm{G}} \\
\text { (vestir-se) }\end{array}$ & $\begin{array}{c}\text { IND }_{\mathrm{G}} \\
\begin{array}{c}\text { (participar da vida da } \\
\text { comunidade) }\end{array}\end{array}$ & $\begin{array}{c}\mathrm{IND}_{\mathrm{G}} \\
\text { reler bam } \\
\text { reacionamento) }\end{array}$ & $\underset{\substack{\text { (ter disponibilidade de } \\
\text { recursos) }}}{\mathrm{IND}_{\mathrm{G}}}$ \\
\hline Área Verde & 0,46 & 0,71 & 0,64 & 0,79 & 0,93 & 0,15 \\
\hline Seis de Maio & 0,40 & 0,66 & 0,66 & 0,64 & 0,81 & 0,61 \\
\hline Santa Catarina & 0,48 & 0,62 & 0,58 & 0,68 & 0,81 & 0,29 \\
\hline TOTAL & 0,45 & 0,66 & 0,63 & 0,70 & 0,85 & 0,35 \\
\hline
\end{tabular}

Fonte: Elaborado pelas autoras a partir dos dados primários da pesquisa de campo.

Se fossem adotadas as faixas de classificação do $\mathrm{IDH}^{5}$ (baixo, médio e alto) para o caso do $I N D_{G}$, poder-se-ia argumentar que a pobreza alta está em: "ter disponibilidade de recursos", "ter acesso ao conhecimento", "ter trabalho gratificante" e "ter perspectiva de futuro". Uma pobreza média é encontrada nos funcionamentos "ter acesso a serviços", "ter boa saúde", "vestir-se adequadamente", "morar bem", "comer adequadamente", "participar da vida da comunidade" e "ter filhos protegidos". Apenas no funcionamento "ter bom relacionamento familiar" que existiria uma pobreza baixa. Seria possível conjecturar que uma possível política de combate à pobreza teria de ter como alvo os funcionamentos "ter disponibilidade de recursos", "ter acesso ao conhecimento", "ter trabalho gratificante" e "ter perspectiva de futuro".

\section{Considerações finais: a noção e as medidas multidimensionais de pobreza e a administração pública}

$\mathrm{O}$ artigo procurou evidenciar que as medidas multidimensionais de pobreza são relevantes para a administração pública, dado que caracterizam melhor a pobreza, aumentando o entendimento de suas causas e auxiliando

\footnotetext{
${ }^{5} \mathrm{O}$ valor do IDH pode ser classificado da seguinte maneira: (a) $0,0 \leq \mathrm{IDH}<0,5$ - baixo desenvolvimento humano; (b) $0,5 \leq \mathrm{IDH}<0,8$ - médio desenvolvimento humano; (c) $0,8 \leq \mathrm{IDH} \leq$ 1,0 - alto desenvolvimento humano. Para mais informações, ver Programa das Nações Unidas para o Desenvolvimento (2007).
} 
na proposta de políticas. Nesse sentido, é relevante o conhecimento sobre as diferentes noções de pobreza e suas respectivas medidas.

Em primeiro lugar, é importante saber qual noção de pobreza está sendo base para cada tipo de política pública, porque, dependendo do conceito adotado, o número e as características de pobres serão diferenciados. Se a renda monetária fosse o único critério para determinar as pessoas mais pobres de um município ou de uma região, tal critério esconderia outras privações existentes e acabaria excluindo ou mal avaliando pessoas que poderiam ser alvo de políticas. Dessa forma, como a pobreza é um fenômeno multidimensional, quando se limita a caracterização da pobreza a uma dimensão - no caso, a renda - , pode-se estar encobrindo as reais privações em outras importantes dimensões, como saúde, educação e proteção familiar, entre outras. Por outro lado, se for adotado o conceito de pobreza como privação de capacitações, é possível entender qual funcionamento de uma pessoa, uma família ou um grupo de pessoas precisa ser atendido para que a política pública obtenha sucesso no combate à pobreza.

Em segundo lugar, se faz necessário analisar quais os impactos da utilização das medidas uni ou multidimensionais de pobreza que servem de base para a elaboração de políticas públicas. Se for utilizada a medida unidimensional para analisar e caracterizar a pobreza, uma política pública de promoção do aumento da renda per capita resultaria em uma redução do número de pobres. No entanto, não é possível afirmar se as pessoas que "deixaram" de ser pobres na dimensão renda tiveram também outras de suas necessidades básicas satisfeitas.

Já as medidas multidimensionais têm um espaço informacional expandido, levando em consideração outros fatores de avaliação como educação, saúde, longevidade, tal como o IDH. Porém, mesmo incluindo outros indicadores na avaliação, as medidas multidimensionais comumente usadas também não expressam adequadamente se os indivíduos deixaram de ser privados em suas dimensões de vida mais valoradas.

Diante dessas discussões, os administradores públicos deveriam analisar a pobreza com base na Abordagem das Capacitações de Sen (1985, 1993, 1999, 2001) e elaborar instrumentos de pesquisa visando a construção de medidas multidimensionais de pobreza, como a calculada para Palmeira das Missões, para tentar descobrir quais são as reais privações sofridas pela população pobre considerando as características e privações particulares de vida na comunidade. A pobreza, por ser um fenômeno multiface, não pode ser plenamente compreendida apenas através da insuficiência de renda. Em muitos casos, as pessoas são pobres por insuficiência de outros fatores. Por exem- 
plo, uma pessoa pode ter maior limitação em uma dimensão como "ter filhos protegidos" se ela residir em um local de maior incidência de criminalidade comparada à dimensão "ter disponibilidade de recursos". Assim, a pobreza precisa ser entendida por meio de medidas multidimensionais que considerem o maior número possível de dimensões que são importantes para a vida das pessoas pobres.

Além disso, uma política pública de combate à pobreza será mais efetiva se atender as dimensões corretas. Ou seja, se pensarmos no exemplo acima em que as pessoas não podem realizar o funcionamento "ter os filhos protegidos", a política de combate à pobreza passaria por medidas de redução da violência. Não adiantaria uma política pautada em distribuição de recursos, uma vez que as pessoas continuariam pobres na "dimensão ter filhos protegidos".

A medida multidimensional de pobreza calculada nesse artigo para as mulheres de Palmeira das Missões mostra que mais limitação existe na realização dos funcionamentos: "ter disponibilidade de recursos", "ter acesso ao conhecimento", "ter trabalho gratificante" e "ter perspectiva de futuro". Média limitação está na realização dos funcionamentos "ter acesso serviços", "ter boa saúde", "vestir-se adequadamente", "morar bem", "comer adequadamente", "participar da vida da comunidade" e "ter filhos protegidos"; e apenas na realização do funcionamento "ter bom relacionamento familiar" existiria uma baixa limitação.

Nesse sentido, este estudo caracteriza-se como uma tentativa de mostrar que através de medidas multidimensionais, como a calculada para o município de Palmeira das Missões, é possível descobrir em qual dimensão de vida a população é mais privada, e, assim, focalizar as políticas públicas para melhor suprir essas necessidades. É interessante notar que o conceito de pobreza pode influenciar o sucesso de certa política, dado que é necessário conhecer não somente quem são os pobres, mas, especialmente, em quais dimensões esses pobres possuem maiores privações.

\section{Referências}

BALATCHANDIRANE, G. Gender discrimination in education and economic development: a study of South Korea, China and India. International Studies, n. 40, p. 349-378, 2003.

BARROS, R.; CARVALHO, M.; FRANCO, S. O Índice de Desenvolvimento Familiar (IDF). Brasília: Ipea, 2003. (Texto para discussão n. 986) 
BIONDO, F. How can we assess a distributive policy? Sen and Rawls on the currency of distributive justice. In: CONFERENCE ON JUSTICE AND POVERTY: EXAMINING SEN'S CAPABILITY APPROACH, 2001, Cambridge. Disponível em: <www. st-edmunds.cam.ac.uk/vhi>. Acesso em: 1o dez. 2002.

CODES, A.L.M. A trajetória do pensamento científico sobre pobreza: em direção a uma visão complexa. Brasília: Ipea, 2008. (Texto para discussão n. 1.332)

COMIM, F.; BAGOLIN, I.P. Aspectos qualitativos da pobreza no Rio Grande do Sul. Ensaios FEE, Porto Alegre, v. 23, n. especial, p. 467-490, 2002.

LADERCHI, C.R. Do concepts matter? An empirical investigation of the differences between a capability and a monetary assessment of poverty. In: CONFERENCE ON JUSTICE AND POVERTY: EXAMINING SEN'S CAPABILITY APPROACH, 2001, Cambridge. Disponível em: <www.st-edmunds.cam.ac.uk/vhi>. Acesso em: $1^{\circ}$ dez. 2002.

NUSSBAUM, M.C. Women and human development: the capabilities approach. Cambridge: Cambridge University Press, 2000.

PICOLOTTO, V.C. Pobreza como privação de capacitações no Rio Grande do Sul. In: ENCONTRO DE ECONOMIA DA REGIÃO SUL, 8, 2005, Porto Alegre. Anais... Porto Alegre: Anpec Sul, 2005.

PROGRAMA DAS NAÇÕES UNIDAS PARA O DESENVOLVIMENTO, 1997. Human development report 1997: human development to eradicate poverty. New York: Oxford University Press, 1997.

,2000. Human development report 2000: human rights and human development - for freedom and solidarity. New York: Oxford University Press, 2000.

. Human development report 2007/2008: fighting climate change - human solidarity in a divided world. New York: Oxford University Press, 2007.

RAWLS, J. Uma teoria da justiça. São Paulo: Martins Fontes, 1997.

SANTOS, L.M. dos. Pobreza como privação de liberdade: um estudo de caso na favela do Vidigal no Rio de Janeiro. Dissertação (Mestrado em Economia) — Programa de Pós-Graduação em Economia, Universidade Federal Fluminense, Rio de Janeiro, 2007.

SCHNEIDER, A.; RAMIRES, V.R. Primeira infância melhor: uma inovação em política pública. Brasília: Unesco, Secretaria de Saúde do Estado do Rio Grande do Sul, 2007.

SEN, A. Poverty and famines: An essay an entitlement and deprivation. Oxford: Clarendon Press, 1981. 
. Well-being, agency and freedom (the Dewey Lectures, 1984). The Journal of Philosophy, v. 82, n. 4, p. 169-221, 1985.

. Capability and well-being. In: NUSSBAUM, M.; SEN, A. (Ed.). The quality of life. Oxford: Oxford University Press, 1993. p. 30-53. . Development as freedom. New York: Anchor Books, 1999. . Desenvolvimento como liberdade. São Paulo: Companhia das Letras, 2000. . Desigualdade reexaminada. Rio de Janeiro: Record, 2001. . Rationality and freedom. London: The Belknap Press of Harvard University Press, 2002. 1997. ; FOSTER, J. On economic inequality. New York: Oxford University Press, SILVA, M.; BARROS, R. Pobreza multidimensional no Brasil. In: ENCONTRO NACIONAL DE ECONOMIA, 34, 2006, Salvador. Anais eletrônicos... Salvador: Anpec, 2006. Disponível em: <www.anpec.org.br/encontro_2006.htm>. Acesso em: 10 jul. 2007.

VERO, J. A comparison of poverty according to resource, functioning and capability: the case of French school leaver's surveys. In: CONFERENCE ON JUSTICE AND POVERTY: EXAMINING SEN'S CAPABILITY APPROACH, 2001, Cambridge. Disponível em: <www.st-edmunds.cam.ac.uk/vhi>. Acesso em: 1o dez. 2002.

WAQUIL, P.; MATTOS, E.J. Pobreza rural e urbana no Rio Grande do Sul: uma análise além da renda. In: CONGRESSO DA SOBER, 41, 2003, Juiz de Fora. Anais... Juiz de Fora: Sober, 2003. 